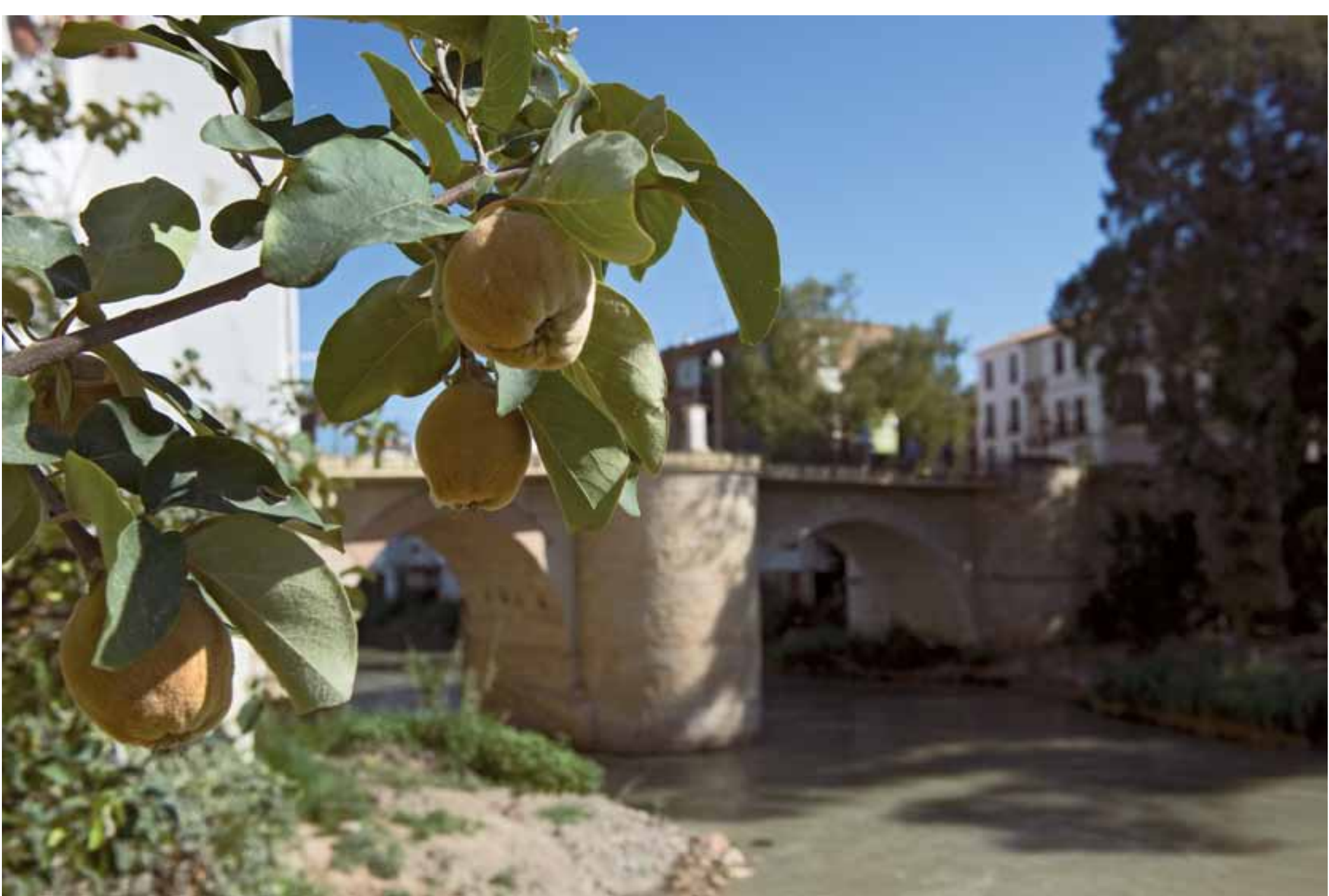

Membrillos junto al puente del Genil en Puente Genil. Foto: Juan Carlos Cazalla, IAPH 


\section{Las latas de carne de membrillo de Puente Genil: de bien efímero a bien mueble museable}

Manuel Córdoba Ruiz, doctorando de la Universidad de Córdoba
La industria membrillera y en menor medida la industria aceitera de Puente Genil han generado un rico patrimonio mueble conformado sobre todo por las llamadas "latas" que es como denominamos a los envases fabricados con hojalata. Las latas de membrillo atraían la atención del consumidor potencial desde las estanterias de la tienda de comestibles y eran uno de los más poderosos medios de sugestión y de afianzamiento del producto.

Entre las fábricas de carne de membrillo, cuyo conocimiento sólo nos lo proporcionan los envases metálicos, se encuentran las de Francisco Chacón, la de Julio Moreno, Manuel Velasco, La Purisima Concepción, San José, Desiderio Martínez, Manuel Baena, La Milagrosa, José Delgado, Colón, Emilio Pérez, Los Apóstoles, Miguel Chacón y Compañía, Francisco y José Luis Ostos y Manuel Estepa.

Muchas de las hojalatas para el envasado procedian de la factoria Societé Génerale de Cirages Francaise de Santander, G. de Andreis M. E. de Badalona y M. Sanguineti del Puerto de Santa María. Las láminas de hojalata eran litografiadas por especialistas que estampaban una imagen imperecedera para el imaginario colectivo y un mismo motivo era reproducido por las empresas para distintas firmas agroalimentarias de España.

La estampación litográfica sobre metal ha dado lugar a obras de considerable interés, con trabajos de diseño que son merecedores de una consideración como producto publicitario, aunque son pocos los bocetos y diseños originales que permiten conocer el proceso de elaboración completo de los trabajos. En su mayor parte se trata de una actividad realizada por manos anónimas.

La procedencia de los modelos iconográficos de las estampaciones que encontramos en los envases de carne de membriIlo de Puente Genil, en muchos casos, obedecen a los motivos impuestos por los catálogos de las fábricas de hojalata, que ofrecian un muestrario sin marca comercial, a fin de que las empresas alimentarias eligieran sus logotipos y eslóganes. La estampación suele ser plana, aunque hay ejemplares repujados, generalmente de motivos florales, cuyo resalte da una mayor vistosidad a la pieza.

Las empresas confiaban en las cajas de lata que aseguran una publicidad mantenida durante mucho tiempo en la casa del cliente, una vez que había consumido la carne de membrillo, un producto con propiedades nutricionales y "curativas" para los problemas digestivos, como hacen constar algunos de los envases.

En épocas de crisis económica se cuida más la presentación del producto y a medida que las técnicas y la industria avanzan, los modelos son más sofisticados, ligeros y prácticos. La eclosión definitiva de este tipo de envases metálicos, que en un principio sólo estuvo reservado para las clases acomodadas, tuvo lugar en la década de 1920, cuando las máquinas sustituyeron a las trabajadoras en la producción. Además, son bastantes las conserveras que mantienen el diseño de sus envases inalterado durante décadas.

Uno de los ejemplares más antiguos conservados en Puente Genil es de 1898, perteneciente a la fábrica de Rafael Rivas. De las dos primeras décadas del pasado siglo existe un nutrido número de envases de gran belleza, como los que reproducen la Reina Victoria, de la firma La Fama o los de la fábrica de Aguilar Solano, de 1914.

La lata ha pasado de ser un bien efímero a ser un objeto codiciado por los coleccionistas en Internet. El pontanés Antonio Illanes sigue siendo uno de los mayores coleccionistas de latas de membrillo, aunque cediera parte de esta colección a la actual firma membrillera San Lorenzo; pero es de "propiedad anónima" la mayoritaria de estas latas. Por tanto, se sobrepasó la finalidad con la que fueron creados los envases de membrillo y su belleza y funcionalidad hicieron que se utilizaran como cofres para conservar dulces, como costureros, para guardar fotografías antiguas o los viejos cromos... En los lugares más deprimidos, las tapaderas de las latas con los temas del santoral se colocaban en los zaguanes de las viviendas. 


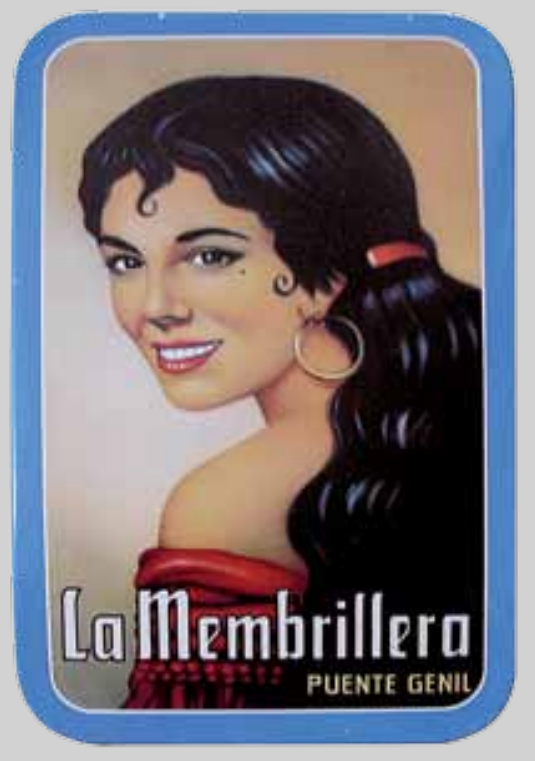

Rostro de gitana en un envase de La Membrillera Industrial.

Foto: Manuel Córdoba Ruiz

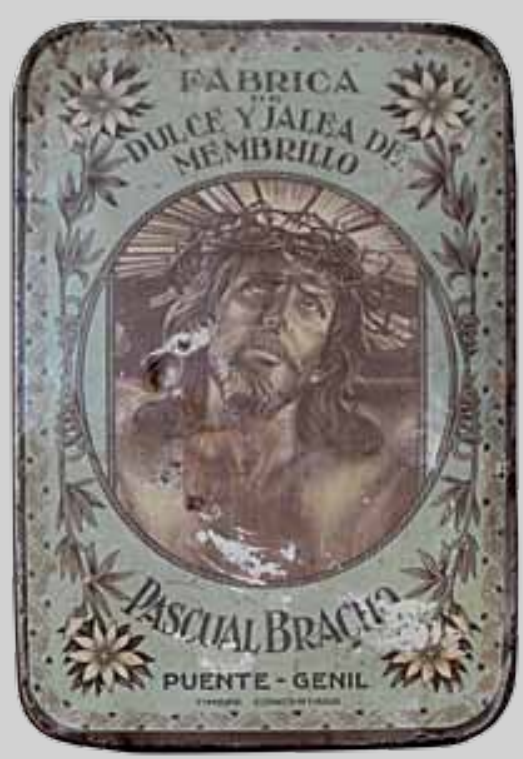

Lata con la imagen del Crucificado. Membrillera de Pascual Bracho. Foto: Manuel Córdoba Ruiz

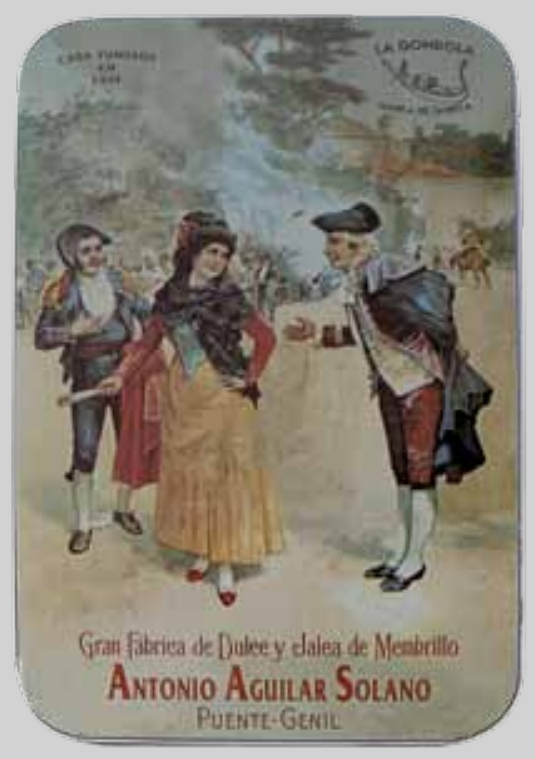

El cortejo. Escena goyesca en un envase de Antonio Aguilar Solano. Foto: Manuel Córdoba Ruiz
Los envases de membrillo son muy variados en cuanto a las estampaciones, que se fueron acomodando a las modas de cada época. Casi todos los envases presentan formato rectangular y sobre la tapadera suele aparecer la marca de la casa, guirnaldas con motivos frutales o florales... adornando el motivo principal. Los costados suelen aprovecharse para imprimir el nombre de la fábrica.

El mismo motivo puede aparecer litografiado en distintos tonos (sepia, rojo o azul), en distintos tamaños. También se incluyen textos en inglés de cara a la exportación del producto y se detallan nombres que suelen evolucionar con el paso del tiempo. El logotipo de la firma es un distintivo de marca, como el león con la balanza de Membrillo Estrada, el águila con rueda dentada, símbolo de progreso de Chacón Yerón o el escudo de Puente Genil. Los premios a la calidad del producto se hacen constar también en las latas, siendo la membrillera San Lorenzo una de las que recibió mayor número de ellos, desde los años 40 del pasado siglo.

La maquinaria que se emplea en el proceso de producción se suele detallar en algunos envases ("Modelo a vapor") para hacer alarde de los avances tecnológicos del proceso de fabricación. Además, existen envases que fueron realizados con motivo de una efemérides especial, como el que creó la fábrica La Andaluza con motivo de la Exposición Iberoamericana.

Hay casos en los que se rescata un tema de un envase antiguo para ser recreado en uno actual, como sucede con las latas de motivos goyescos; y también tendriamos que hacer una distinción entre los envases con motivos seriados y los que imprimian una estampa típicamente pontana, como el puente sobre el río Genil, el paraje conocido como El Tarajal, la fábrica de harinas de La Alianza o la imagen de Jesús Nazareno. La membrillera El Quijote, en uno de sus envases más recientes, ha contribuido a difundir la candidatura de Córdoba 2016 como Capital Cultural, con una imagen nocturna de la MezquitaCatedral.

Los estilos que aparecen en los envases de membrillo pontanos son muy variados: Art Decó, clasicismo, cubismo, costumbrismo o realismo en los temas más populares. Hay ejemplares excepcionales, en los que se utiliza el color oro, que daba a las latas un aspecto luminoso y elegante, pero con el fin de los años 20 del pasado siglo se abre una etapa en la que lo funcional se impone sobre lo decorativo.

En los envases más antiguos se aprecia la influencia del grafismo británico, que desde mediados del siglo XIX se impone poco a poco. La gráfica impresa victoriana, abigarrada, multicolor y ecléctica va más allá de la función propagandistica, recreando orlas, cartelas, grecas,...

En la actualidad resulta "preocupante" la abusiva utilización de la reproducción fotográfica, puesto que desciende la creatividad que durante décadas ha caracterizado a los profesionales de la gráfica industrial. 


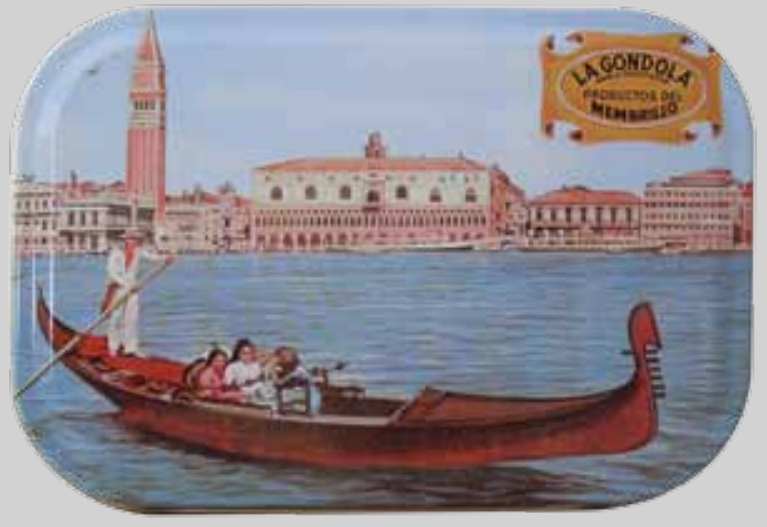

Gondolero veneciano. Membrillera La

Góndola.

Foto: Manuel Córdoba Ruiz

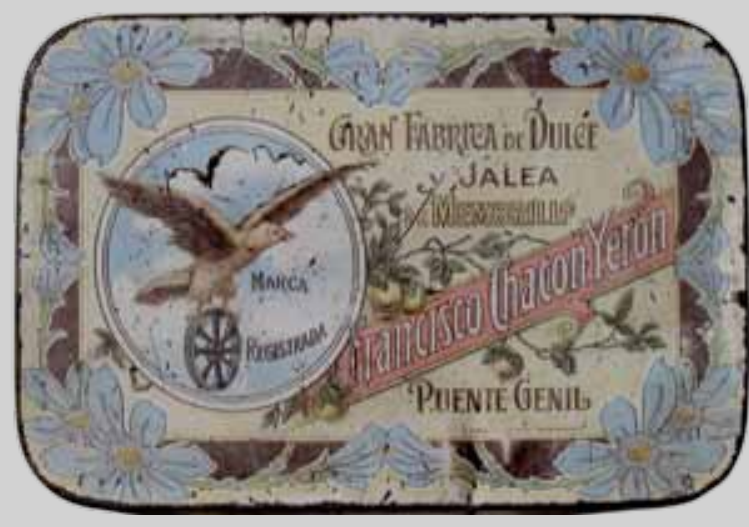

Águila con rueda dentada del progreso.

Fábrica de Francisco Chacón Yerón.

Foto: Manuel Córdoba Ruiz

\section{ICONOGRAFÍA DE LAS LATAS DE MEMBRILLO}

El motivo costumbrista y popular se impone sobre el resto de temas en las latas de membrillo de Puente Genil. Los envases actuales apenas muestran variedad de motivos y las cuatro fábricas membrilleras existentes continúan con los mismos modelos de hace años, que son fácilmente reconocibles. La iconografía religiosa abunda junto a otros temas, como las estampas de mundos exóticos, las escenas de pinturas pompeyanas o los motivos chinescos. La temática infantil es muy común en escenas en las que se muestran niños rollizos que prestan su imagen sana y bien nutrida para difundir el goloso postre.

Con la pretensión de exportar sus productos a paises extranjeros, las industrias membrilleras recurren al motivo folklórico, con la clásica mujer de rasgos raciales agraciados, de mantilla y con abanico, ataviada con el traje típico valenciano o en escenas de baile por bulerías.

De temática religiosa se han conservado un gran número de envases. Aparecen representados una parte significativa de la iconografia cristifera y mariana, asi como imágenes de santos y ángeles, si bien el tema por excelencia es el de la Inmaculada, patrona de Puente Genil. Otras veces la imagen religiosa da nombre a la fábrica y es la misma marca del producto.

Dentro de las escenas sobre la vida de Cristo podemos encontrar el Nacimiento, la Sagrada Familia, El Divino Pastor de Murillo, La
La lata, que ha traspasado su propia función de envase, ha pasado de ser un bien efímero a ser un objeto codiciado por los coleccionistas en Internet 
Sagrada Cena de Leonardo, el Corazón de Jesús y el Gran Poder de Sevilla.

Entre los temas marianos recurrentes, como hemos apuntado, aparece la Inmaculada. Las estampaciones responden a los modelos populares de Murillo de la Inmaculada de Soult del Museo del Prado o del Escorial, procedentes de estampas de la época. Los envases de membrillo de Puente Genil dan cabida a otro tipo de representaciones de la Virgen como la advocación de la Medalla Milagrosa, la Virgen del Carmen o la Dolorosa. Otras representaciones marianas que podemos encontrar son las de la Virgen de la Mercedes, la Divina Pastora, la Esperanza Macarena en distintas versiones, la Virgen de la Esperanza de Puente Genil, la Virgen del Valle o el icono del Perpetuo Socorro.

De las imágenes de santos podemos encontrar a San Pascual, San Lorenzo, San Antonio de Padua, Santiago a caballo o Santa Teresa.

Otras escenas recogen estampas folklóricas, exóticas y turisticas, como el Parque del Retiro, el Patio de los Leones de la Alhambra, la Venecia de los canales, el monumento de Vitorio Enmanuel de Roma... Entre las latas con temas históricos encontramos episodios que afianzaron cierto patriotismo y filiación al régimen imperante: las carabelas de Colón, la batalla de Clavijo o la Reina Victoria Eugenia, en una lata de la membrillera de Rafael Rivas que resultó polémica ya que no se pidió permiso a la Casa Real para difundir la imagen de la soberana.

En las escenas costumbristas de las latas de membrillo aparece con frecuencia la mujer, los festines o el amor. Los motivos florales son muy habituales, al igual que los temas mitológicos y alegóri- cos que generalmente están relacionados con la marca de la casa. Pueden aparecer también animales, como los gatos de la lata de la fábrica de Julio Moreno Melgar, que se consumía en la Casa Real española y era un regalo que cada año hacian los condes de Casa Padilla.

Entre los motivos goyescos encontramos temas como La danza, La vendimia, La gallina ciega, La maja y los embozados o escenas de cortejo.

El descubrimiento de las pinturas murales romanas de Pompeya influyó en que se reprodujeran escenas pictóricas en los envases, en firmas membrilleras como la de Campos. Personajes como arlequines, duendes, peleles, se suman a los temas literarios que aparecen en las litografias de envases de membrillo, con pasajes de Dante o escenas de El Quijote -banquete de Sancho Panza (parte II, capítulo 47).

Finalmente, el fruto del membrillo, materia prima del postre pontano, cosechado en muchas ocasiones en las mismas riberas del Genil, es representado en las latas de membrillo como parte de un bodegón, en forma de guirnaldas, mostrado por niños o mujeres, durante el proceso de recolección...

Las latas de membrillo, por ser un documento en metal de un pasado industrial glorioso y por traspasar la función de continente de un producto que ha dado fama mundial a la población de Puente Genil, merecen ser conservadas y musealizadas. En ellas podemos ver la evolución de los estilos y modas y materializan una forma de hacer publicidad, una vez que se consumía el producto, llegando a nuestros días.

\section{En la web}

\section{DIPUTACIÓN PROVINCIAL DE CÓRDOBA www.dipucordoba.es}

El sitio web de esta institución pública ofrece información de interés sobre la campiña de Córdoba, fichas descriptivas de los municipios que la conforman con datos sobre su patrimonio cultural.

\section{CONSEJO REGULADOR DE LA DENOMINACIÓN DE ORIGEN DE BAENA}

www.dobaena.com

Información sobre la comarca, la importancia del olivar en sus municipios, así como de las empresas que conforman el Consejo Regulador organizadas por tipo de actividad, forman parte de los contenidos que ofrece este sitio web.

\section{CONSEJO REGULADOR DE LA \\ DENOMINACIÓN DE ORIGEN MONTILLA-MORILES \\ Www.montilla-moriles.org}

En esta web podrá consultar datos sobre las zonas y localidades de producción de la Denominación de Origen Montilla-Moriles, clasificación de los vinos de la denominación, bodegas y acceso a la ruta del vino Montilla-Moriles.

\section{ASOCIACIÓN CULTURAL AMIGOS DE ATEGUA \\ www.ategua.es}

Sitio de la asociación dedicada al conocimiento del yacimiento arqueológico de Ategua (Santa Cruz, Córdoba). Ofrece el acceso a numerosos recursos de información sobre el yacimiento, tales como actividades, el programa de las VIII Jornadas Culturales sobre el yacimiento de Ategua, imágenes, noticias de prensa, artículos y publicaciones, entre otros.

\section{MUSEO DEL OLIVAR Y EL ACEITE DE BAENA}

www.museoaceite.com

Fuente de referencia sobre la relación de Baena con el olivar y el aceite. Historia de la ciudad, cultivo del olivar, producción, clasificación de aceites, simbología del olivo, son algunos de los apartados de este sitio web.

\section{INSTITUTO DE LA SAL}

www.institutodelasal.com

Organismo sin ánimo de lucro que representa el sector de la sal en España y Portugal. En este sitio web podrá encontrar información sobre todo lo que rodea al mundo de la sal, como su historia o la de la industria salinera en España, acompañado de audiovisuales e infografías.

\section{SALINAS DEL INTERIOR. BLOG SOBRE LOS PAISAJES DE LA SAL Www.salinasdeinterior.org}

Blog de la Asociación Salinas del Interior (Guadalajara). Acceso a la publicación digital El Alfoli, con numerosos artículos dedicados a las salinas. Podrá consultar noticias nacionales e internacionales, enlaces y publicaciones.

\section{MUSEO HISTÓRICO MUNICIPAL DE BAENA www.baena.es}

Sitio web del Ayuntamiento de Baena donde se da acceso a información sobre esta institución dedicada a conservar el patrimonio histórico y arqueológico de Baena. La colección se encuentra organizada en diferentes apartados, desde el Paleolítico a la Edad Moderna. Y se completa con el boletín Baena arqueológica. 